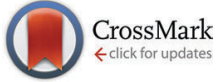

Cite this: New J. Chem., 2016, 40, 1297

Received (in Montpellier, France) 14th April 2015

Accepted 3rd August 2015

DOI: $10.1039 / c 5 n j 00925 a$

www.rsc.org/njc

\section{Synthesis, electrochemical and photophysical studies of the borondifluoride complex of a meta-linked biscurcuminoid $\dagger$}

\author{
Morgane Rivoal, Elena Zaborova, Gabriel Canard, Anthony D'Aléo* and \\ Frédéric Fages
}

\begin{abstract}
The synthesis of the borondifluoride complex of a biscurcuminoid system is described, and its electrochemical and photophysical properties are compared to those of a series of monochromophoric models. The data show that the meta-linked biscurcuminoid exhibits enhanced optical properties in solution, such as high optical brightnesses obtained at one- and two-photon excitation $\left(B^{1}=87000 \mathrm{M}^{-1} \mathrm{~cm}^{-1}\right.$ and $B^{2}=313 \mathrm{GM}$, respectively). UV/visible absorption of solid-state particles formed in water solution revealed that the four investigated dyes are strongly aggregated and fluorescence spectroscopy showed that they are emissive in the NIR with fluorescence quantum yields spanning from 1.5 to $12.5 \%$. In the case of the meta-linked biscurcuminoid, a high brightness is obtained using one- and two-photon excitation $\left(B^{1}=6952 \mathrm{M}^{-1} \mathrm{~cm}^{-1}\right.$ and $B^{2}=70 \mathrm{GM}$, respectively). Such red-shifted emission combined with a yet significant brightness in the solidstate is believed to arise from the choice of the meta-linkage which limits strong intermolecular packing.
\end{abstract}

\section{Introduction}

The design of organic dyes with tailored optical properties is of utmost importance for applications in advanced fields such as bioimaging, ${ }^{1}$ photodynamic therapy, ${ }^{2}$ theranostics, display ${ }^{3}$ and telecommunication technologies, ${ }^{4}$ and photovoltaics. ${ }^{5-7}$ In that context, compounds displaying high molar absorption coefficients, large two-photon absorption cross sections, high luminescence quantum yields in solution and in the solid state, large Stokes shifts, high thermal and photochemical stability represent attractive candidates as fluorescent reporters. Especially, dyes that emit in the near infrared (NIR, wavelengths longer than $700 \mathrm{~nm}$ according to The International Commission on Illumination) using two-photon excitation in the NIR region are of great interest for use in cell imaging because both excitation and detection operate in the biological transparency window.

Among the many classes of organic dyes, boron complexes, such as borondipyrromethene (BODIPY) compounds, ${ }^{8-11}$ are particularly attractive. In addition of the interesting optical properties in solution, many borondifluoride complexes (other than BODIPY) have also been shown to yield rather efficient photoluminescent behavior in the solid state. ${ }^{12}$ In particular, compounds deriving from acetylacetonate ligand have shown

Aix Marseille Université, CNRS, CINAM UMR 7325, Campus de Luminy, Case 913, 13288 Marseille, France. E-mail: daleo@cinam.univ-mrs.fr

$\dagger$ Electronic supplementary information (ESI) available. See DOI: 10.1039/ c5nj00925a interesting properties such as high two-photon absorption cross sections, ${ }^{13,14}$ mechano-fluorochromic behaviors ${ }^{15,16}$ and efficient NIR emissions ${ }^{17,18}$ that led to their use for cells imaging ${ }^{19}$ or as sensors of volatile acid/base, ${ }^{20,21}$ fluorescent reporters for amyloid, ${ }^{22,23}$ optical sensors for anaerobic environment ${ }^{24}$ and electron donors in solar cells. ${ }^{25}$

Recently, we and others have shown that curcuminoid structures containing the borondifluoride unit represent efficient emitters that fulfill many of the previous requirements. However, our work also led to the conclusion that solid-state fluorescence of $\mathrm{BF}_{2}$ complexes of curcuminoids arose from highly stacked chromophores. Such interactions could explain the emission occurring in the NIR but inherently induce efficient face-to-face quenching, which limit the fluorescence quantum yield $\left(\Phi_{\mathrm{f}}\right)$ to ca. 5\%. ${ }^{17,18}$ These results led us to consider dye 4 (Chart 1) in which two curcuminoid subunits are covalently connected via a meta-phenylene linker. Indeed, this structural design has proven to be successful in the case of electroluminescent conjugated polymers such as poly(phenylenevinylene)s because the metalinkage was observed to inhibit interchain interactions and excimer formation in the condensed phase, thereby ensuring brighter emission than in the para-linked counterparts. ${ }^{26}$ The introduction of three aliphatic long chains at the meta-phenylene bridge in $\mathbf{4}$ was anticipated to further limit solid-state interchromophoric interactions and to provide a higher solubility in organic solvents for the extended structure. As a result, compound $\mathbf{4}$ features a non symmetrical curcuminoid system, which required the investigation of the model compound 3 that 
<smiles>COc1ccc(/C=C2/C=C(/C=C/c3ccc(OC)cc3)OB(F)O2)cc1</smiles><smiles>COc1cc(OC)c(/C=C/C2=CC(/C=C/c3c(OC)cc(OC)cc3OC)=C(F)OB2F)c(OC)c1</smiles>

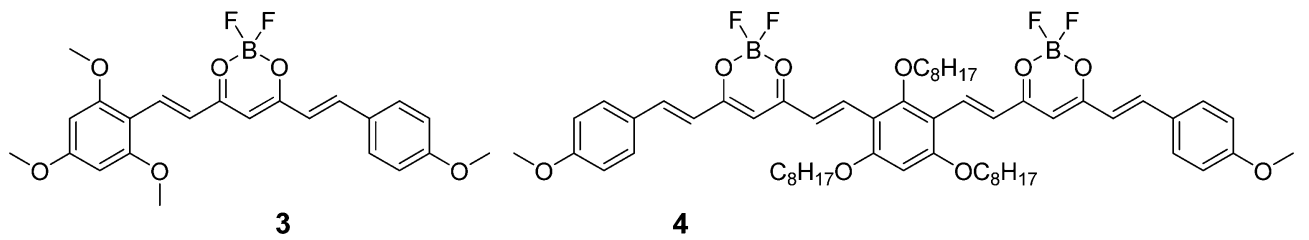

Chart 1 Molecular structures of the borondifluoride curcuminoid derivatives.

possesses a non symmetrical structure as well. Compounds 1 and 2 served as models to estimate the electronic influence of the electron donor (D) peralkylated phloroglucinol ring in the photophysical investigation.

We report herein the synthesis of compounds 1-4 and a study of their electrochemical and optical properties in organic solvents. The two-photon excited fluorescence (TPEF) properties of the four dyes were characterized in solution. We describe the preparation and fluorescence emission of organic nanoparticles of 1-4. Our approach gives a strategy toward the design of extended biscurcuminoids with improved emission ability in both the solution and the solid states.

\section{Results and discussion}

\section{Synthesis}

The synthetic routes toward 1-4 are outlined in Scheme 1. The borondifluoride complexes $\mathbf{1}$ and $\mathbf{2}$ were prepared using a previously reported procedure. ${ }^{27}$ Syntheses of the unsymmetrical $\mathrm{BF}_{2}$ complexes 3 and 4 required first of all the preparation of the hemicurcuminoid 5. Similarly to what has been published, ${ }^{28}$ this intermediate was prepared by a Knoevenagel reaction using an excess of acetylacetone (acac/aldehyde 3:1), which provided the compound 5 in a reasonable yield of $60 \%$. Then, the reaction of the intermediate 5 with one equivalent of 2,4,6-trimethoxybenzaldehyde afforded the ligand Lig 3 . Lig 4 was prepared in a yield of $34 \%$ by reacting two equivalents of 5 with 1,3,5-tris(n-octyloxy)benzaldehyde.

Complexation to boron difluoride was performed by reacting the ligands with a slight excess of the boron trifluoride etherate in dichloromethane solution (DCM). The dyes were purified by crystallization or, when necessary, by column chromatography. Dyes 1-4 were obtained as highly colored solids and characterized by ${ }^{1} \mathrm{H}$ - and ${ }^{19} \mathrm{~F}$-NMR spectroscopies and by high resolution mass spectrometry (HRMS).

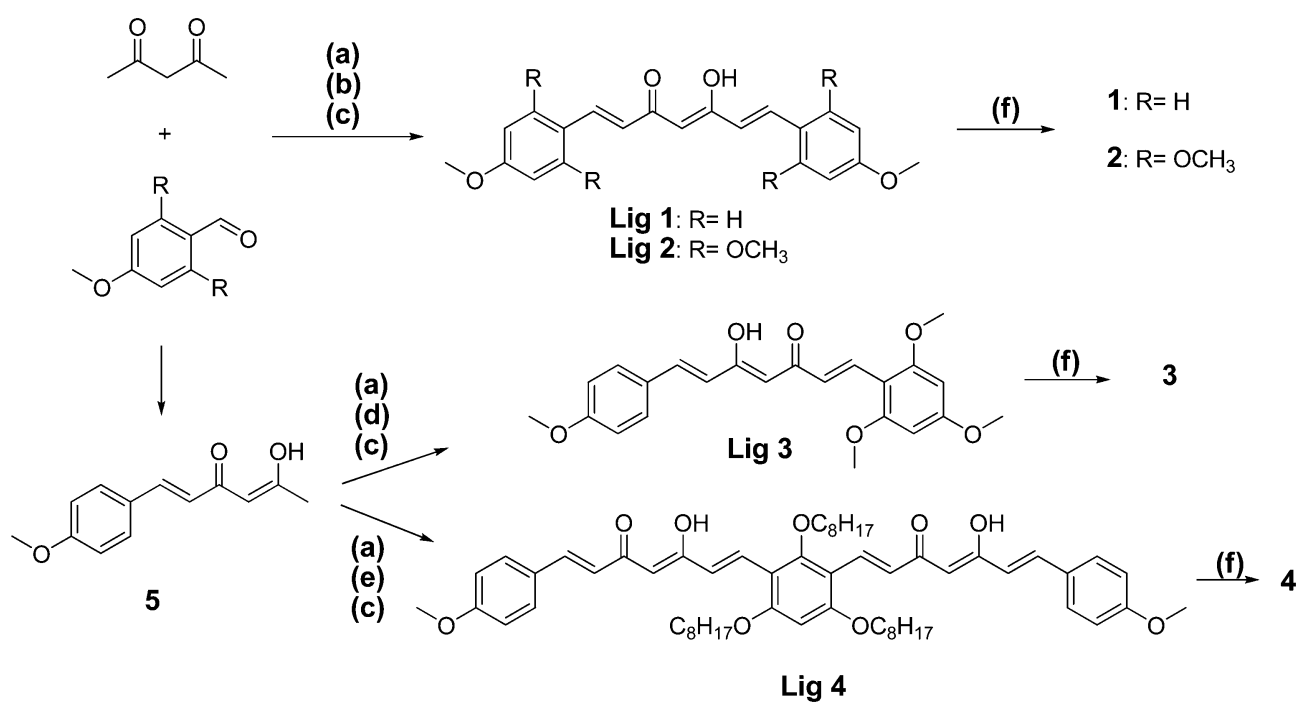

Scheme 1 Syntheses of the borondifluoride curcuminoid derivatives $1,2,3$ and 4 . (a) $\mathrm{B}_{2} \mathrm{O}_{3}$, ethylacetate, $60{ }^{\circ} \mathrm{C}$; (b) anisaldehyde, tri- $n$-butylborane, ethylacetate, $60{ }^{\circ} \mathrm{C}$; (c) $n$-butylamine, ethylacetate, $80{ }^{\circ} \mathrm{C}$, then $\mathrm{HCl}, 60^{\circ} \mathrm{C}$; (d) $2,4,6$-trimethoxybenzaldehyde, tri- $n$-butylborane, ethylacetate, $60{ }^{\circ} \mathrm{C}$; (e) 2,4,6-tris(octyloxy)isophthalaldehyde, tri-n-butylborane, ethylacetate, $60^{\circ} \mathrm{C}$; (f) $\mathrm{BF}_{3} \cdot \mathrm{Et}_{2} \mathrm{O}, \mathrm{DCM}$, reflux. 


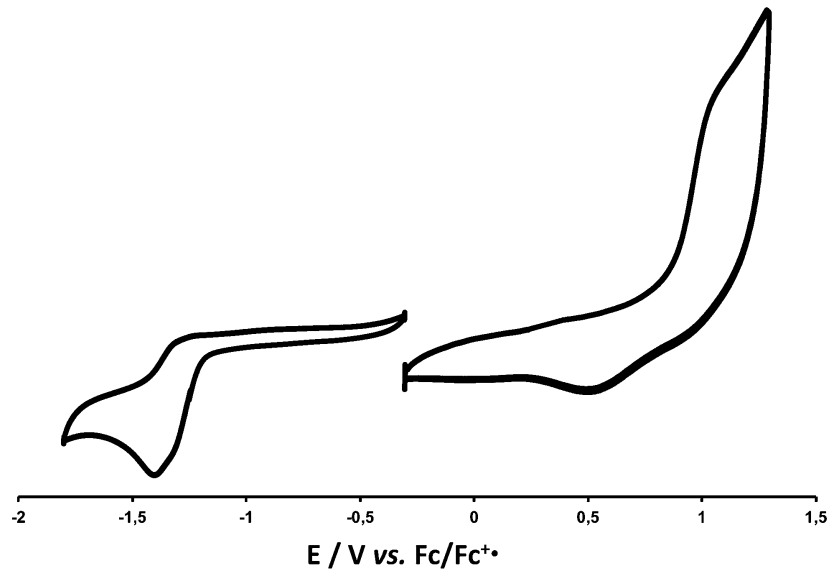

Fig. 1 Cyclic voltammogram of the bis borondifluoride complex 4 in DCM solution containing 0.1 M $\left[\left({ }^{n} \mathrm{Bu}_{4} \mathrm{~N}\right) \mathrm{PF}_{6}\right]$ (scan rate of $100 \mathrm{mV} \mathrm{s}^{-1}$ ).

Table 1 Oxidation and reduction half-wave potential values for the studied dioxaborine derivatives $(10 \mu \mathrm{M})$ in dichloromethane solution vs. $\mathrm{Fc} / \mathrm{Fc}^{+} \cdot$ using tetrabutylammonium hexafluorophosphate as electrolyte $(100 \mu \mathrm{M})$, the values are given in volt

\begin{tabular}{lllll}
\hline & $E_{1 / 2}^{\mathrm{red}}$ & $\left(E_{1 / 2}^{\mathrm{ox}}\right)_{1}$ & $\left(E_{1 / 2}^{\mathrm{ox}}\right)_{2}$ & $\Delta E_{\mathrm{g}}{ }^{a}$ \\
\hline $\mathbf{1}$ & -1.27 & 1.10 & $-^{b}$ & 2.37 \\
$\mathbf{2}$ & -1.44 & 0.72 & 1.09 & 2.16 \\
$\mathbf{3}$ & -1.37 & 0.89 & 1.31 & 2.26 \\
$\mathbf{4}$ & -1.30 & 1.05 & $-^{b}$ & 2.35
\end{tabular}

${ }^{a}$ Electrochemical HOMO-LUMO gap $\Delta E_{\mathrm{g}}=\left(E_{1 / 2}^{\mathrm{ox}}\right)_{1}-E_{1 / 2}^{\mathrm{red}} \cdot{ }^{b}$ The second oxidation process occurs at potentials out of the solvent electrochemical window.

\section{Electrochemistry}

The electrochemical properties of dyes 1-4 were investigated in DCM solution containing $0.1 \mathrm{M}$ of $(n-\mathrm{Bu})_{4} \mathrm{NPF}_{6}$. The cyclic voltammograms (CV) are given in Fig. 1 and Fig. S1 (ESI $\dagger$ ) and the oxidation and reduction half-wave potential values $\left(E_{1 / 2} v\right.$ s. ferrocene/ferrocenium) are collected in Table 1.

The four complexes exhibit one-electron oxidation and reduction waves that can be attributed to the donor alkoxysubstituted phenyl (D) end-groups and the acceptor (A) dioxaborine ring, respectively. The first oxidation potential decreases with the strength of the D units, depending on the number of appended methoxy groups (Table 1). In contrast, increasing the donor strength induces a cathodic shift of the reduction potential but overall, the electrochemical gap is decreased by ca. $0.2 \mathrm{~V}$.

The CV of 2 (Fig. S1, ESI $\dagger$ ) clearly shows two successive and well separated one-electron oxidation waves that reflect the electronic communication between trimethoxyphenyl endgroups through the curcuminoid backbone. It can be noted that the first oxidation and reduction potential values of the unsymmetrical complex 3 are intermediate between those of the symmetrical complexes $\mathbf{1}$ and $\mathbf{2}$.

The first oxidation and reduction potential values obtained for $\mathbf{4}$ are closer to those recorded for $\mathbf{1}$ than for $\mathbf{3}$. Furthermore, the HOMO-LUMO electrochemical gap is also very close for both compounds $\mathbf{1}$ and $\mathbf{4}$. These observations suggest that the first oxidation in $\mathbf{4}$ is likely centered on the $p$-methoxy aryl groups. The increase of the oxidation potential in 4 relative to 3 could be due to presence the second curcuminoid moiety. In addition, since both reduction and oxidation processes of $\mathbf{4}$ involve the same number of electrons, we assume that methoxyphenyl end-groups and dioxaborine rings in $\mathbf{4}$ are simultaneously oxidized and reduced, respectively, at the same potential. This effect is in agreement with the reduced conjugation between meta-linked chromophores.

\section{Photophysical study in solution}

The electronic absorption spectra of 1-4 were recorded in DCM solutions (Fig. 2a) and the spectroscopic data are reported in Table 2. The spectra consist mainly of one intense transition band at low energy $(450-550 \mathrm{~nm})$ attributed to a strongly allowed $\pi-\pi^{*}$ transition. A second electronic transition band of much lower intensity appears as a shoulder at higher energy $(<400 \mathrm{~nm}$, vide infra). The spectra of compounds 1-3 display identical shape of the absorption profiles, they only differ by the position of the bands. The increase of donor strength from 1 to 2 induces a red-shift of the electronic transitions. As expected, the unsymmetrical dye 3 absorbs at a wavelength intermediate between those recorded for $\mathbf{1}$ and 2. In contrast, compound 4 exhibits a low-energy absorption band with very different shape, full width at half maximum, and intensity. The molar absorption coefficient determined for $\mathbf{4}$ is twice as high as that of the three other dyes. The more complex shape and the larger Stoke shift of the absorption band is likely to stem from intramolecular excitonic coupling between the two curcuminoid chromophores. This excitonic coupling explains the low value of the optical gap determined for 4 .

The complexes 1-4 are fluorescent in the visible region (540$575 \mathrm{~nm}$ ) upon excitation into the low-energy transition band and exhibit fluorescence quantum yields ranging from 44 to $61 \%$ in DCM. In agreement with electronic absorption data, an increase of the donor strength causes a red-shift of the fluorescence emission from $538 \mathrm{~nm}(\mathbf{1})$ to $574 \mathrm{~nm}$ (4). It is worth noting that the highest value of $\Phi_{\mathrm{f}}(61 \%)$ is obtained for complex 4 , giving a high brightness value of $c a .87000 \mathrm{M}^{-1} \mathrm{~cm}^{-1}$.

The solvent dependence of absorption and emission properties was studied for the four borondifluoride complexes (Tables S1 and S2, ESI $\dagger$ ). Both electronic UV/visible absorption and fluorescence emission spectra undergo a bathochromic shift and lose their vibronic structures when solvent polarity increases (Fig. S3-S6, ESI $\dagger$ ). These features show that the Franck-Condon excited state $S_{1}$ is more polar in nature than the ground state. Furthermore, the positive slope of the Lippert-Mataga plots reveals that, in those systems, the relaxation occurs toward a solvent-equilibrated charge transfer (CT) singlet excited state along with an increase of dipole moment with respect to the ground state (Fig. S2, ESI $\dagger$ ). ${ }^{29}$

The fluorescence intensity of compounds 1-3 continuously increases with increasing solvent polarity. Both solvatochromism and the negative solvatokinetic behavior suggest the formation of an emissive CT state. The fact that the fluorescence lifetimes also 

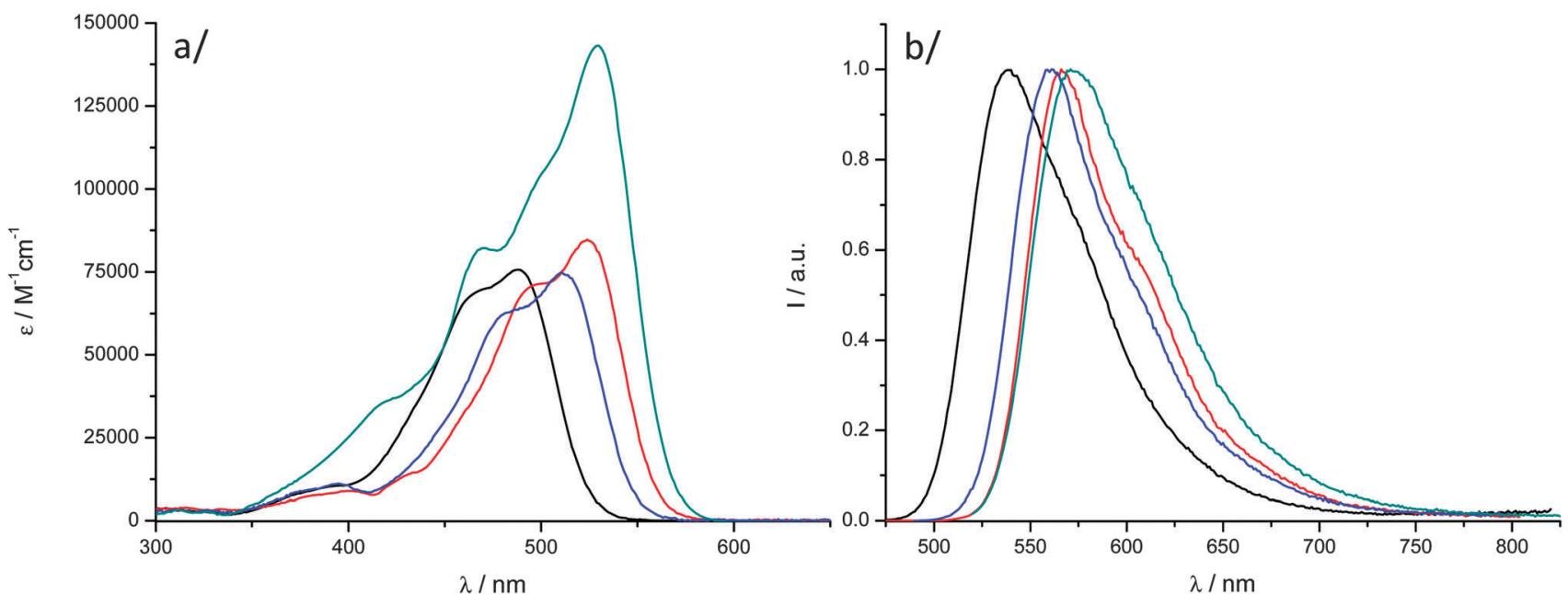

Fig. 2 (a) Overlaid electronic absorption spectra and (b) overlaid corrected normalized fluorescence emission spectra (conc. $\approx 10^{-6} \mathrm{M}$. $\lambda_{\text {exc }}$ at the absorption maximum) of $\mathbf{1}(-), 2(-), \mathbf{3}(-)$ and $\mathbf{4}(-)$ recorded in DCM at room temperature.

increase with solvent polarity leads to constant values of the radiative rate constants $k_{\mathrm{f}}$ for the three dyes (1-3). Concomitantly, the nonradiative rate constants $k_{\mathrm{nr}}$ decreases in polar solvents. The case of $\mathbf{4}$ is different. Upon increasing solvent polarity, the fluorescence quantum yield first increases (negative solvatokinetics) then decreases (positive solvatokinetics), a maximum being observed. The positive solvatokinetic behavior of 4 in polar solvent suggests an enhanced population of a highly polar CT state prone to a strong nonradiative deactivation. At this stage, the peculiar photophysical behavior of $\mathbf{4}$ remains unclear.

Two-photon excited fluorescence emission and excitation spectra of 1-4 were recorded in the 700-1000 $\mathrm{nm}$ wavelength range using a femtosecond Ti-Sapphire pulsed laser source, according to the experimental protocol described by Webb et al. using coumarin-307 and rhodamine $\mathrm{B}$ as references. ${ }^{30}$ The observation of a quadratic dependence of the fluorescence intensity versus incident laser power at several wavelengths unambiguously confirmed that the origin of the fluorescence emission can be assigned to a TPA process in DCM solution (Fig. S7, ESI $\dagger$ ). In the experimental laser power range used for these measurements, we checked that no saturation or photodegradation occurred. The two-photon excitation spectra of $\mathbf{1}$, 2, 3 and 4 in DCM are shown in Fig. 3 and Fig. S9 (ESI $\dagger$ ) and the corresponding data are reported in Table 2. As reported elsewhere, ${ }^{14} 1$ has a TPA cross section $\left(\sigma^{\mathrm{TPA}}\right)$ of $155 \mathrm{GM}$ at $770 \mathrm{~nm}$ while dye 2 , containing stronger donating groups, has its maximum red-shifted to $810 \mathrm{~nm}$ with a larger $\sigma^{\text {TPA }}$ value of ca. $248 \mathrm{GM}$. It is interesting to note that 3 presents an intermediate $\sigma^{\mathrm{TPA}}$ value of $208 \mathrm{GM}$ at $790 \mathrm{~nm}$. For dye 4 , as already observed for the molar absorption coefficient, the two-photon cross section is slightly more than twice (i.e. $513 \mathrm{GM}$ ) the value determined for 3. This gives a two-photon brightness of $313 \mathrm{GM}$, that is much higher than those obtained with the model borondifluoride complexes 1-3.

As noticed previously for curcumin ${ }^{31}$ and borondifluoride complexes of curcuminoids, ${ }^{14}$ the TPA band of the four complexes

Table 2 Spectroscopic data and photophysical properties of all borondifluoride compounds solvated in DCM and as particles in water at room temperature ${ }^{a}$

\begin{tabular}{|c|c|c|c|c|c|c|c|c|c|c|c|c|}
\hline \multirow[b]{2}{*}{ Compound } & \multicolumn{2}{|c|}{ UV-vis } & \multicolumn{7}{|c|}{ Fluorescence } & \multicolumn{3}{|l|}{ TPEF } \\
\hline & $\lambda_{\mathrm{abs}}$ & $\varepsilon_{\max }$ & $\lambda_{\mathrm{em}}$ & $\Delta \nu_{\mathrm{ST}}$ & $\Phi_{\mathrm{f}}$ & $B^{1}$ & $\tau_{\mathrm{f}}$ & $k_{\mathrm{f}}$ & $k_{\mathrm{nr}}$ & $\lambda_{\max }^{2}$ & $\sigma^{\mathrm{TPA}}$ & $B^{2}$ \\
\hline 1 (DCM) & 488 & 75480 & 538 & 1904 & 0.44 & 33211 & 1.30 & 3.4 & 4.3 & 770 & 155 & 68 \\
\hline 2 (DCM) & 524 & 84860 & 566 & 1416 & 0.52 & 44127 & 1.72 & 3.0 & 2.8 & 810 & 248 & 129 \\
\hline 3 (DCM) & 511 & 74510 & 561 & 1957 & 0.46 & 34275 & 1.74 & 2.6 & 3.1 & 790 & 208 & 96 \\
\hline 4 (DCM) & 529 & 143140 & 574 & 1421 & 0.61 & 87315 & 1.69 & 3.6 & 2.3 & 800 & 513 & 313 \\
\hline 1 (water) & 451 & 34170 & 710 & $8088^{b}$ & 0.06 & 2050 & 6.44 & 0.09 & 1.5 & 780 & 210 & 13 \\
\hline 2 (water) & 489 & 27380 & 717 & $6503^{b}$ & 0.035 & 783 & $\begin{array}{l}1.32 \\
2.91^{c}\end{array}$ & - & - & $-^{d}$ & $-^{d}$ & $-^{d}$ \\
\hline 3 (water) & 407 & 29500 & 711 & $10505^{b}$ & 0.015 & 443 & $\begin{array}{l}2.13 \\
6.01^{c}\end{array}$ & - & - & $-^{d}$ & $-^{d}$ & $-^{d}$ \\
\hline 4 (water) & 468 & 55620 & 692 & $6917^{b}$ & 0.125 & 6952 & $\begin{array}{l}1.89 \\
6.64^{c}\end{array}$ & - & - & 850 & 560 & 70 \\
\hline
\end{tabular}

${ }^{a}$ Absorption maximum wavelengths $\lambda_{\text {abs }}(\mathrm{nm})$; molar absorption coefficients at maximum $\varepsilon_{\max }\left(\mathrm{M}^{-1} \mathrm{~cm}^{-1}\right)$; fluorescence maximum wavelengths $\lambda_{\mathrm{em}}(\mathrm{nm})$; Stokes shifts $\Delta \nu_{\mathrm{ST}}\left(\mathrm{cm}^{-1}\right)$; fluorescence quantum yields $\Phi_{\mathrm{f}}$; brightness $B=\Phi_{\mathrm{f}} \times \varepsilon\left(\mathrm{M}^{-1} \mathrm{~cm}^{-1}\right)$; fluorescence lifetimes $\tau_{\mathrm{f}}(\mathrm{ns})$; radiative $k_{\mathrm{f}}\left(10^{8} \mathrm{~s}^{-1}\right)$ and nonradiative $k_{\mathrm{nr}}=\left(1-\Phi_{\mathrm{f}}\right) / \tau_{\mathrm{f}}\left(10^{8} \mathrm{~s}^{-1}\right)$ rate constants; two-photon absorption maximum $\lambda_{\max }{ }^{2}(\mathrm{~nm})$; two-photon cross section $\sigma^{\text {TPA }}(\mathrm{GM})$; two-photon brightness $B^{2}=\Phi_{\mathrm{f}} \times \sigma^{\mathrm{TPA}}(\mathrm{GM}) .{ }^{b}$ Pseudo-Stokes shift determined using the maximum absorption. ${ }^{c}$ A biexponential decay was found. ${ }^{d}$ Not determined due to high scattering of light with those particles. 

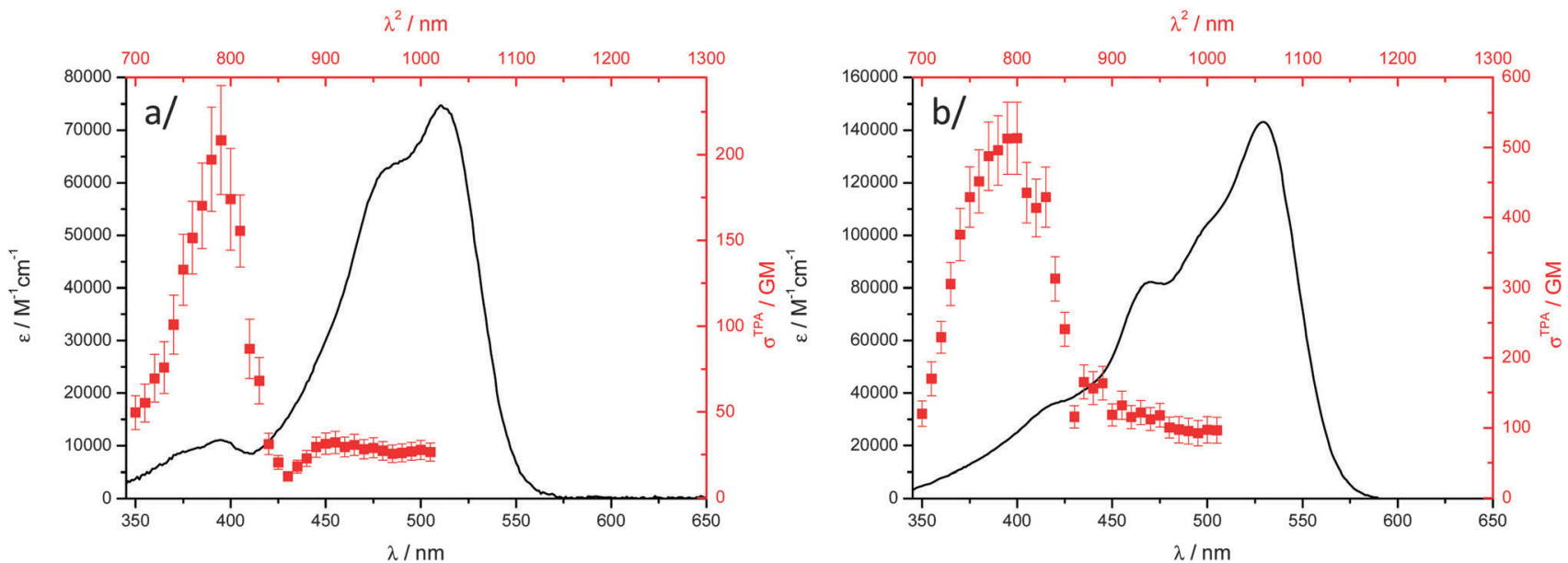

Fig. 3 Two-photon excitation ( $\square$, higher $x$-coordinate and —, right $y$-coordinate) with their error bars, OPA spectra $(-$, lower $x$-coordinate and - , left $y$-coordinate) in DCM: (a) dye 3 and (b) dye 4.

does not match the one-photon transition as it is strongly blueshifted, corresponding to the two-photon allowed transition at higher energy mentioned previously. The lowest-energy transitions of 1-4 are not completely TPA forbidden: $\sigma^{\mathrm{TPA}}$ values of $c a$. 10-15, 30-35, 25-30 and 100 GM were measured for $\mathbf{1}, 2,3$ and $\mathbf{4}$, respectively (Fig. 3 and Fig. S8, ESI†). Such situation is often encountered for D-A-D chromophores ${ }^{32-35}$ and, in the case of free curcumin, Hernández et al. have shown that the $\mathrm{S}_{0}-\mathrm{S}_{2}$ transition was more TPA-allowed than the $\mathrm{S}_{0}-\mathrm{S}_{1}$ transition. However, a much weaker contribution from the $\mathrm{S}_{0}-\mathrm{S}_{1}$ transition was still observed. ${ }^{31}$
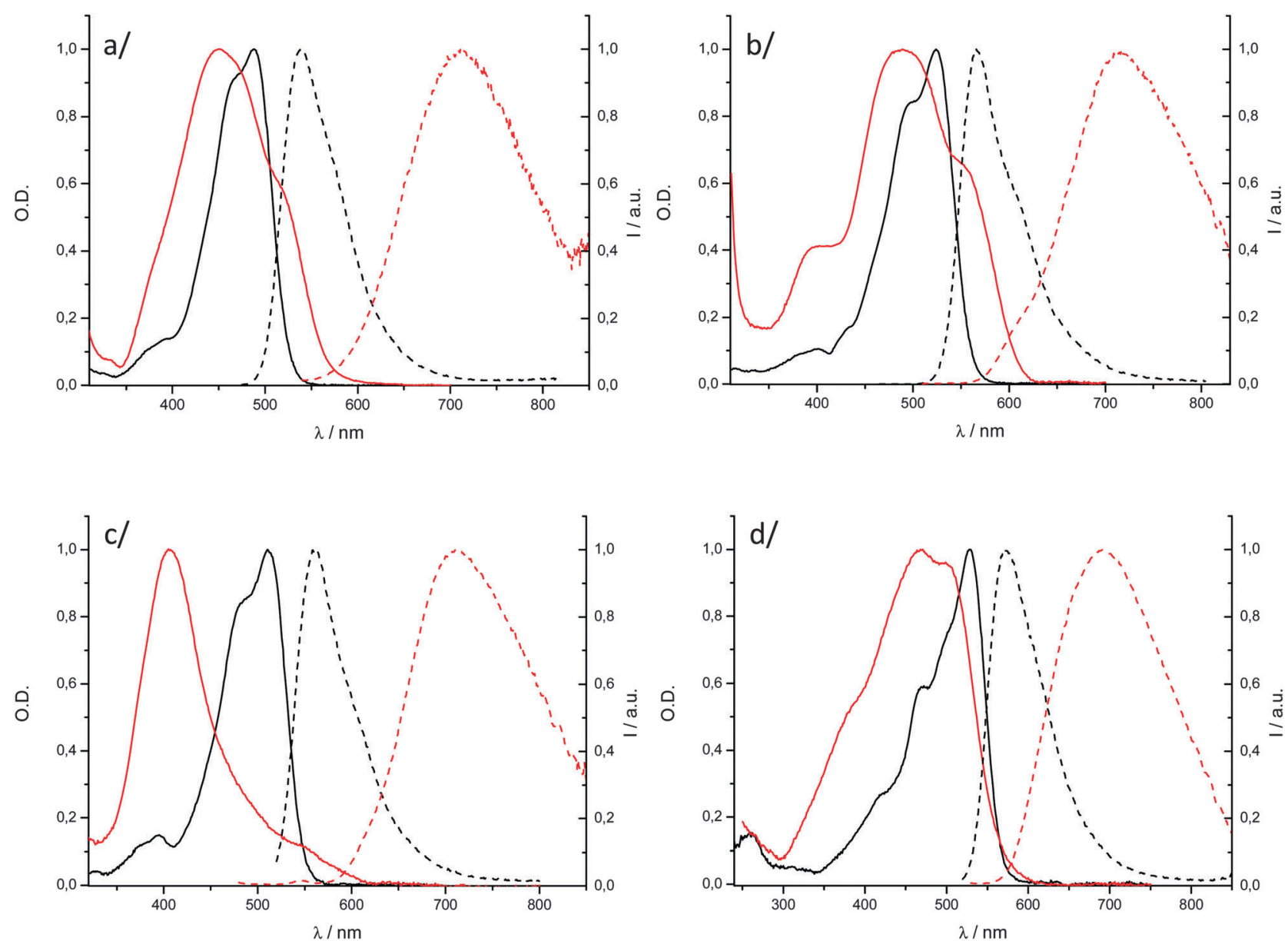

Fig. 4 Overlaid absorption (solid lines) and emission (dashed lines) spectra of DCM solutions (black) and particles in water (red) for (a) 1; (b) 2; (c) $\mathbf{3}$ and (d) $\mathbf{4}$. 


\section{Solid-state optical properties}

We prepared solid-state particles, P-2-P-4, by quickly adding a concentrated THF solution of the dyes $\mathbf{2 - 4}$ into water according to the classical fast precipitation method. ${ }^{36}$ The so-obtained suspensions enabled the measurement of the UV/visible absorption and fluorescence spectra of the aggregated molecules. We reported the preparation of $\mathbf{P - 1}$ in a previous publication $^{\mathbf{1 4}}$ and the resulting spectroscopic data are recalled here for the sake of comparison. The shape of the electronic absorption spectra of P-1-P-4 is strongly affected relative to the solution spectra showing that Davydov splitting is occurring within such dyes. The absorption profiles of P-1, P-2 and P-4 (Fig. 4a, b, and d, respectively) are complex, broad, and their maximum presents a hypsochromic shift (ca. 30-60 nm). These observations show that excitonic interactions prevail in the condensed phase, which could be correlated with singlecrystal X-ray diffraction data in the case of $\mathbf{1}$. Such complex structure is in line with Davydov splitting into high- and lowenergy transitions. The absorption spectrum of P-3 displays a very different effect (Fig. 4c). The low-energy transition is considerably blue-shifted (of $c a .96 \mathrm{~nm}$ ) and has a narrower shape as compared to those of the above mentioned particles P-1, P-2 and P-4. These spectroscopic features are the signature of $\mathrm{H}$-aggregation in the solid state for compound 3. Noticeably, P-4, also containing unsymmetrical curcuminoid chromophores, does not adopt such arrangement.

Particles P-2-P-4 fluoresce in the NIR, from 692 to $717 \mathrm{~nm}$ (Fig. 4, Table 2). The spectra are considerably red-shifted (superior to $95 \mathrm{~nm}$ ) as compared to those obtained in solution in the highly polar acetonitrile solvent (Fig. S3-S6, ESI $\dagger$ ). Such long emission wavelengths can be attributed to chromophore packing in the solid state, as shown by X-ray diffraction for $\mathbf{P - 1}$ and by electronic absorption spectroscopy for the others (Fig. 4). The fluorescence quantum yields of P-1-P-3 are found in the range of $1.5-6.0 \%$ which are significant values for aggregated organic dyes emitting in the NIR. Not surprisingly, the H-aggregated compound 3 affords the lowest value of $1.5 \%$. Remarkably, the $\Phi_{\mathrm{f}}$ of dye 4 reaches a substantial value of $12.5 \%$ in the solid state, which makes P-4 a very bright solid-state NIR fluorophore (brightness at $700 \mathrm{~nm}$ of $6952 \mathrm{M}^{-1} \mathrm{~cm}^{-1}$ ). Actually, a rather large part of emitted photons by the four compounds have energies below $700 \mathrm{~nm}$ because the particle emission spectra are broad. However, it can be highlighted that, when only photons at longer wavelength than $700 \mathrm{~nm}$ are integrated, dye 4 remains the most luminescent borondifluoride complex of the series with a NIR luminescence quantum yield of $c a$. $6.5 \%$ while the other three dyes have quantum yields of 4.0, 1.5 and $1.0 \%$, respectively.

In addition, two-photon properties of $\mathbf{P 4}$ could be measured and compared to the previously reported P1 particles. Noticeably, the $\mathbf{P 2}$ and $\mathbf{P 3}$ particles could not be measured due to the much higher light scattering in those samples which precluded the obtention of reliable data. As observed in DCM solution and for $\mathbf{P 1}$ in water, the two-photon maximum of $\mathbf{P 4}$ does not overlap the maximum of the one photon absorption $S_{0}-S_{1}$

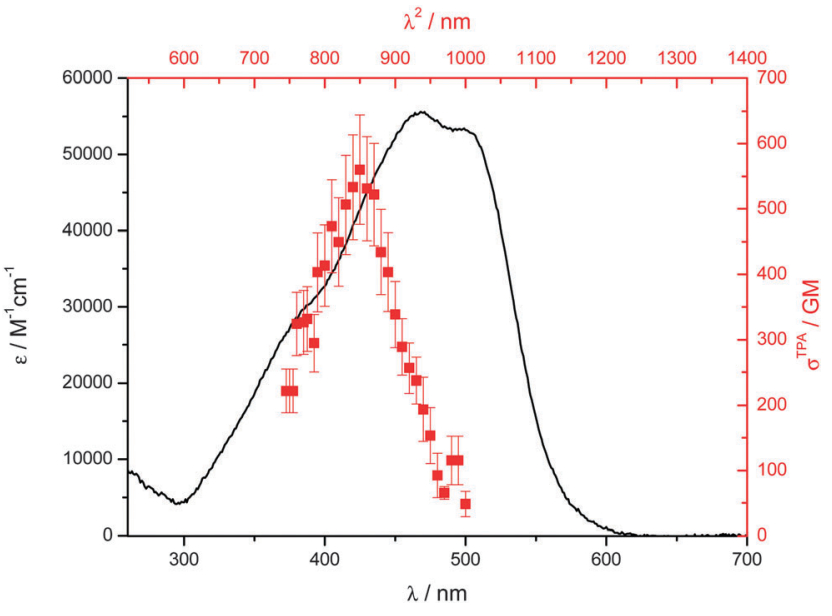

Fig. 5 Two-photon excitation ( $\square$, higher $x$-coordinate and - right $y$-coordinate) with their error bars, OPA spectra (-, lower $x$-coordinate and - , left $y$-coordinate) of $\mathbf{P 4}$ in water.

transition (Fig. 5) but it better matches the $\mathrm{S}_{0}-\mathrm{S}_{2}$ one (vide supra). This maximum is located at $850 \mathrm{~nm}$ with a two-photon cross section of ca. 560 GM. Such two-photon cross section value is 2.5 times higher than that of P1 which, associated to the higher fluorescence quantum yield of $\mathbf{P 4}$, results in a much higher two-photon brightness for $\mathbf{P 4}$ (more than 5 times greater than the one of P1).

\section{Conclusion}

We have described the synthesis of three borondifluoride complexes of curcuminoid derivatives, 2-4. Compound 4 contains two curcuminoid subunits connected via a meta-position of an aryl linkage, and as such it represents a first example of a new class of extended biscurcuminoids. The electrochemical investigations show the interruption of conjugation in $\mathbf{4}$, the two chromophoric subunits behaving independently. However, the absorption spectrum reveals that an intramolecular excitonic interaction exists in solution, showing that the two chromophoric units are not optically independent. Compound $\mathbf{4}$ displays a high fluorescence quantum yield, and a good value of the twophoton absorption cross section, which makes it an attractive fluorophore. Compounds 2-4 are fluorescent in the solid state with wavelengths reaching the NIR. Like 1-3, compound 4 experience intermolecular interactions in the condensed phase. However, it exhibits the higher value of fluorescence quantum yield within the series investigated, which may result from the meta-linkage that limits strong $\pi-\pi$ stacking with respect to the monochromophoric analogues. Indeed, the unsymmetrical model compound 3 forms $\mathrm{H}$-aggregates, which illustrates the strong propensity of monochromophoric curcuminoids to form tightly packed solid-state arrangements. These findings should help in the design of new fluorophores with improved NIR emitting properties in solution and in the solid state for imaging applications. 


\section{Experimental}

\section{Material and steady state spectroscopy}

Materials and Instrumentation. All solvents for synthesis were of analytic grade. Spectroscopy measurements were carried out with spectroscopic grade solvents. NMR spectra $\left({ }^{1} \mathrm{H} .{ }^{13} \mathrm{C} .{ }^{19} \mathrm{~F}\right)$ were recorded at room temperature on a BRUKER AC 250 operating at 400,100, and $425 \mathrm{MHz}$ for ${ }^{1} \mathrm{H},{ }^{13} \mathrm{C}$, and ${ }^{19} \mathrm{~F}$, respectively. Data are listed in parts per million (ppm) and are reported relative to tetramethylsilane $\left({ }^{1} \mathrm{H}\right.$ and $\left.{ }^{13} \mathrm{C}\right)$; residual solvent peaks of the deuterated solvents were used as internal standards. Mass spectra were realized in Spectropole de Marseille (http://www.spectropole.fr/). Solid state spectra and luminescence quantum yield were measured using an integrating sphere. UV/Vis-absorption spectra were measured on a Varian Cary 50. Emission spectra were measured on a Horiba-JobinYvon Fluorolog-3 spectrofluorimeter that was equipped with a three-slit double-grating excitation and a spectrograph emission monochromator with dispersions of $2.1 \mathrm{~nm} \mathrm{~mm}^{-1}$ (1200 grooves $\mathrm{mm}^{-1}$ ). Steady-state luminescence excitation was done using unpolarized light from a 450W xenon CW lamp and detected at an angle of $90^{\circ}$ for dilute-solution measurements (10 $\mathrm{mm}$ quartz cell) and with a red-sensitive Hamamatsu R928 photomultiplier tube. Special care was taken to correct NIR-emission spectra that were obtained with the latter device. The detector was corrected according to the procedure described by Parker et al. ${ }^{37}$ The observed photomultiplier output $A_{1}$ was recorded at a wavelength $\lambda$, which corresponds to the apparent emission spectrum. $A_{1}$ is given by [eqn (1)], where $F_{1}$ and $S_{1}$ are the corrected emission spectrum and the spectroscopic sensitivity factor of the monochromatorphotomultiplier setup, respectively.

$$
A_{1}=\left(F_{1}\right)\left(S_{1}\right) / \lambda^{2}
$$

To calculate $S_{1}$, we used 4 - $N, N$-dimethylamino-4'-nitrostilbene (DMANS) as a standard NIR fluorophore for which its corrected emission spectrum has been precisely determined. ${ }^{38}$ Luminescence quantum yields $\left(\Phi_{\mathrm{f}}\right)$ were measured in dilute DCM solutions with an absorbance below 0.1 by using [eqn (2)], where $\mathrm{OD}(\lambda)$ is the absorbance at the excitation wavelength $(\lambda), n$ the refractive index, and $I$ the integrated luminescence intensity.

$$
\Phi_{\mathrm{fx}} / \Phi_{\mathrm{fr}}=\left[\mathrm{OD}_{\mathrm{r}}(\lambda) / \mathrm{OD}_{\mathrm{x}}(\lambda)\right]\left[I_{\mathrm{x}} / I_{\mathrm{r}}\right]\left[n_{\mathrm{x}} / n_{\mathrm{r}}\right]^{2}
$$

Subscripts " $r$ " and " $x$ " stand for reference and sample, respectively. The luminescence quantum yields were not corrected by the refractive indices. We used ruthenium trisbipyridine bischloride in water $\left(\Phi_{\mathrm{fr}}=0.021\right)$ as a reference for compounds that absorbed in the $450 \mathrm{~nm}$ region, while rhodamine B $\left(\Phi_{\mathrm{fr}}=0.49\right)$ in EtOH was used for excitation between 540 and $560 \mathrm{~nm}$.

Lifetime measurements were carried out on a HORIBA Jobin Yvon IBH FluoroLog-3 spectrofluorimeter that was adapted for time-correlated single-photon counting. For these measurements, pulsed LEDs with an appropriate wavelength were used. Emission was monitored perpendicular to the excitation pulse and spectroscopic selection was achieved by a passage through the spectrograph. A thermoelectrically cooled single-photon-detection module (HORIBA Jobin Yvon IBH, TBX-04-D) incorporating a fast-rise-time photomultiplier tube, a wide-bandwidth preamplifier, and a picosecond-constant fraction discriminator was used as the detector. Signals were acquired using an IBH DataStation Hub photon counting module and data analyses were performed by using the commercially available DAS 6 decay-analysis software package from HORIBA Jobin Yvon IBH; the reported $\tau$ values are given with an estimated uncertainty of about $10 \%$.

Cyclic voltammetric (CV) data were acquired using a BAS 100 Potentiostat (Bioanalytical Systems) and a PC computer containing BAS100W software (v2.3). A three-electrode system with a Pt working electrode (diameter $1.6 \mathrm{~mm}$ ), a Pt counter electrode and an $\mathrm{Ag} / \mathrm{AgCl}$ (with $3 \mathrm{M} \mathrm{NaCl}$ filling solution) reference electrode was used. $\left[(n \mathrm{Bu})_{4} \mathrm{~N}\right] \mathrm{PF}_{6}(0.1 \mathrm{M}$ in dichloromethane) served as an inert electrolyte. Cyclic voltammograms were recorded at a scan rate of $100 \mathrm{mV} \mathrm{s}^{-1}$. Ferrocene was used as internal standard. ${ }^{39}$

\section{Synthetic procedure}

Dye 1, its ligand (Lig 1), ${ }^{27}$ the ligand of 2 (Lig 2), ${ }^{40} 2,4,6$ tris(octyloxy)isophthalaldehyde ${ }^{41}$ and (1E,4Z)-5-hydroxy-1-(4methoxyphenyl)hexa-1,4-dien-3-one $\left(\right.$ Lig 5) ${ }^{28}$ were prepared as previously reported.

General synthesis of Lig 1 and Lig 2. In a $50 \mathrm{~mL}$ round bottom flask, a solution of the acetylacetonate derivative ( $1 \mathrm{~mol}$ eq.) and $\mathrm{B}_{2} \mathrm{O}_{3}(0.5 \mathrm{~mol}$ eq.) dissolved in ethyl acetate $(15 \mathrm{~mL})$ was stirred at $60{ }^{\circ} \mathrm{C}$ for $30 \mathrm{~min}$. A solution of the appropriate aldehyde ( $1 \mathrm{~mol}$ eq.) and tri( $n$-butyl)borane ( $1 \mathrm{~mol}$ eq.) in ethyl acetate $(10 \mathrm{~mL})$ was added and the resulting mixture was stirred for $30 \mathrm{~min}$ at $60{ }^{\circ} \mathrm{C}$. A catalytic amount of $n$-butylamine $(0.4 \mathrm{~mol}$ eq.) was then added and the reaction mixture was refluxed overnight. After cooling to $60{ }^{\circ} \mathrm{C}, 30 \mathrm{~mL}$ of $0.4 \mathrm{M} \mathrm{HCl}$ were added and the mixture stirred for $30 \mathrm{~min}$. After cooling, the precipitate was filtered off and dried in vacuo to yield pure ligands Lig 1 and Lig 2.

Synthesis of $5((1 E, 4 Z)-5$-hydroxy-1-(4-methoxyphenyl)hexa1,4-dien-3-one). In a $50 \mathrm{~mL}$ round bottom flask, a solution of acetylacetone $(3.00 \mathrm{~g}, 30 \mathrm{mmol})$ and $\mathrm{B}_{2} \mathrm{O}_{3}(1.050 \mathrm{~g}, 15 \mathrm{mmol})$ dissolved in ethyl acetate $(10 \mathrm{~mL})$ was stirred at $60{ }^{\circ} \mathrm{C}$ for $30 \mathrm{~min}$. A solution of anisaldehyde $(1.36 \mathrm{~g}, 10 \mathrm{mmol})$ and tri $(n-$ butyl)borane $(2.30 \mathrm{~g}, 10 \mathrm{mmol})$ in ethyl acetate $(8 \mathrm{~mL})$ was added and the mixture was stirred for $30 \mathrm{~min}$ at $60{ }^{\circ} \mathrm{C}$. A catalytic amount of $n$-butylamine $(0.44 \mathrm{~g}, 6 \mathrm{mmol})$ was then added to the solution and the reaction mixture was refluxed overnight. After cooling to $60{ }^{\circ} \mathrm{C}, 30 \mathrm{~mL}$ of $0.4 \mathrm{M} \mathrm{HCl}$ were added and the mixture was stirred for $30 \mathrm{~min}$. After cooling, the precipitate was filtered off (Lig 1). The residual solution was evaporated. The oily compound was dissolved in dichloromethane. The organic layer was washed with water, brine, dried over $\mathrm{MgSO}_{4}$ and evaporated to dryness. The oily crude was purified by column chromatography on silica using a mixture of cyclohexane and dichloromethane (gradient from $1 / 1$ to $3 / 1$ ) yielding the pure 5 as a yellowish solid (1.20 g, 55\%).

Synthesis of Lig 3 and Lig 4 . In a $50 \mathrm{~mL}$ round bottom flask, a solution of 5 ( $1 \mathrm{~mol}$ eq.) and $\mathrm{B}_{2} \mathrm{O}_{3}$ (0.5 mol eq.) dissolved in 
ethyl acetate $(10 \mathrm{~mL})$ was stirred at $60{ }^{\circ} \mathrm{C}$ for $30 \mathrm{~min}$. A solution of the appropriate aldehyde ( $1 \mathrm{~mol}$ eq. of aldehyde function) and tri(n-butyl)borane ( 1 mol eq. of aldehyde function) in ethyl acetate $(10 \mathrm{~mL})$ was added and the mixture was stirred for $30 \mathrm{~min}$ at $60{ }^{\circ} \mathrm{C}$. A catalytic amount of $n$-butylamine $(0.5 \mathrm{~mol}$ eq.) was then added to the solution and the reaction mixture was refluxed overnight. After cooling to $60{ }^{\circ} \mathrm{C}, 30 \mathrm{~mL}$ of $0.4 \mathrm{M} \mathrm{HCl}$ were added and the mixture and stirred for $30 \mathrm{~min}$. After cooling, the precipitate was filtered off and dried in vacuo to yield the pure ligands Lig 3 and Lig 4.

Lig 3: ((1E,4Z,6E)-5-hydroxy-7-(4-methoxyphenyl)-1-(2,4,6trimethoxyphenyl)hepta-1,4,6-trien-3-one). Orange solid; yield: $65 \% ;{ }^{1} \mathrm{H}$ NMR (400 MHz, $\left.\mathrm{CDCl}_{3}, \mathrm{ppm}\right): \delta=8.07\left(\mathrm{~d},{ }^{3} J=16.1 \mathrm{~Hz}\right.$, 1H). 7.57 (d, $\left.{ }^{3} J=15.8 \mathrm{~Hz}, 1 \mathrm{H}\right), 7.48\left(\mathrm{~d},{ }^{3} J=8.7 \mathrm{~Hz}, 2 \mathrm{H}\right), 6.98\left(\mathrm{~d},{ }^{3} J=\right.$ $16.1 \mathrm{~Hz}, 1 \mathrm{H}), 6.89$ (d, $\left.{ }^{3} \mathrm{~J}=8.7 \mathrm{~Hz}, 2 \mathrm{H}\right), 6.48\left(\mathrm{~d},{ }^{3} J=15.8 \mathrm{~Hz}, 1 \mathrm{H}\right)$, $6.10(\mathrm{~s}, 2 \mathrm{H}), 5.77(\mathrm{~s}, 1 \mathrm{H}), 3.87(\mathrm{~s}, 6 \mathrm{H}), 3.83(\mathrm{~s}, 3 \mathrm{H}), 3.82(\mathrm{~s}, 3 \mathrm{H}) ;{ }^{13} \mathrm{C}$ NMR (100 MHz, $\left.\mathrm{CDCl}_{3}\right): \delta=186.01,182.18,162.97,161.47$, $161.13,139.27,132.17,129.69,128.13,123.98,122.24,114.41$, 106.57, 101.50, 90.57, 55.85, 55.49, 55.47. HRMS $\left(\mathrm{ESI}^{+}\right)[\mathrm{M}+\mathrm{H}]^{+}$ calcd for $\mathrm{C}_{23} \mathrm{H}_{25} \mathrm{O}_{6}{ }^{+} \mathrm{m} / \mathrm{z}=397.1651$, found $\mathrm{m} / z=397.1650$.

Lig 4: $\quad\left(\left(1 E, 1^{\prime} E, 4 Z, 4^{\prime} Z, 6 E, 6^{\prime} E\right)-1,1^{\prime}-(2,4,6\right.$-tris(octyloxy)-1,3phenylene)bis(5-hydroxy-7-(4-methoxyphenyl)hepta-1,4,6-trien3-one)). Dark orange solid; yield: $34 \%$; ${ }^{1} \mathrm{H}$ NMR $(400 \mathrm{MHz}$, $\left.\mathrm{CDCl}_{3}, \mathrm{ppm}\right): \delta=7.92\left(\mathrm{~d},{ }^{3} J=16.1 \mathrm{~Hz}, 2 \mathrm{H}\right), 7.60\left(\mathrm{~d},{ }^{3} J=15.8 \mathrm{~Hz}\right.$, 2H), 7.49 (d, $\left.{ }^{3} J=8.7 \mathrm{~Hz}, 4 \mathrm{H}\right), 7.04\left(\mathrm{~d},{ }^{3} J=16.1 \mathrm{~Hz}, 2 \mathrm{H}\right), 6.89$ (d, $\left.{ }^{3} J=8.7 \mathrm{~Hz}, 4 \mathrm{H}\right), 6.48$ (d, $\left.{ }^{3} J=15.8 \mathrm{~Hz}, 2 \mathrm{H}\right), 6.23$ (s, 1H), 5.69 $(\mathrm{s}, 2 \mathrm{H}), 4.05\left(\mathrm{t},{ }^{3} J=6.2 \mathrm{~Hz}, 4 \mathrm{H}\right), 3.83(\mathrm{~m}, 6 \mathrm{H}), 3.77\left(\mathrm{t},{ }^{3} J=6.3 \mathrm{~Hz}\right.$, $4 \mathrm{H}), 1.88$ (m, 6H), $1.53(\mathrm{~m}, 6 \mathrm{H}), 1.30(\mathrm{~m}, 24 \mathrm{H}), 0.87$ (m, 9H); ${ }^{13} \mathrm{C}$ NMR (100 MHz, $\mathrm{CDCl}_{3}$ ): $\delta=184.09,183.78,161.66,161.23$, 139.80 , 131.86, 129.78, 128.00, 125.68, 122.29, 114.41, 111.44, 101.76, 92.63, 69.04, 55.47, 31.97, 29.68, 29.53, 29.44, 29.17, 26.42, 26.36, 22.81, 14.23. HRMS $\left(\mathrm{ESI}^{+}\right)[\mathrm{M}+2 \mathrm{H}]^{2+}$ calcd for $\mathrm{C}_{58} \mathrm{H}_{80} \mathrm{O}_{8}{ }^{+} \mathrm{m} / \mathrm{z}=460.2901$, found $\mathrm{m} / \mathrm{z}=460.2903$.

\section{General procedure for borondifluoride complexes}

In a $50 \mathrm{~mL}$ round bottom flask, the ligand (1 mol eq.) was solubilized in dichloromethane $(20 \mathrm{~mL})$ before boron trifluoride etherate (1.1 mol eq.) was added. The reaction mixture was refluxed overnight. After cooling to room temperature, the solvent was evaporated and the resulting solid was suspended in diethyl ether. The precipitate was filtered off yielding the pure complex except for $\mathbf{2}$. For the latter dye, the crude complex was purified by column chromatography using silica gel with a mixture of cyclohexane and dichloromethane $(1 / 4)$.

2: ((1E,4Z,6E)-5-(difluoroboryloxy)-1,7-bis(2,4,6-trimethoxyphenyl)hepta-1,4,6-trien-3-one). Purple solid; yield: $52 \%$; ${ }^{1} \mathrm{H}-$ NMR (400 MHz, $\left.\left(\mathrm{CD}_{3}\right)_{2} \mathrm{CO}, \mathrm{ppm}\right): \delta=8.41\left(\mathrm{~d},{ }^{3} J=15.7 \mathrm{~Hz}, 2 \mathrm{H}\right)$, 7.24 (d, $\left.{ }^{3} J=15.7 \mathrm{~Hz}, 2 \mathrm{H}\right), 6.34(\mathrm{~s}, 4 \mathrm{H}), 6.20$ (s, 1H), 3.98 (s, 12H), $3.92(\mathrm{~s}, 6 \mathrm{H})$; Satisfactory ${ }^{13} \mathrm{C}$ NMR spectra could not be obtained; ${ }^{19} \mathrm{~F}-\mathrm{NMR}\left(\left(\mathrm{CD}_{3}\right)_{2} \mathrm{CO}, 235 \mathrm{MHz}\right): \delta=-141.77\left({ }^{10} \mathrm{~B}\right.$, $0.2 \mathrm{~F}),-142.87\left({ }^{11} \mathrm{~B}, 0.8 \mathrm{~F}\right)$. HRMS $\left(\mathrm{ESI}^{+}\right)[\mathrm{M}+\mathrm{Na}]^{+}$calcd for $\mathrm{C}_{25} \mathrm{H}_{27} \mathrm{O}_{8} \mathrm{BF}_{2} \mathrm{Na}^{+} \mathrm{m} / z=527.1664$, found $m / z=527.1661$.

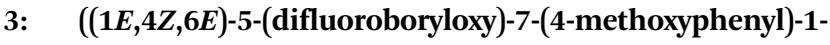
(2,4,6-trimethoxyphenyl)hepta-1,4,6-trien-3-one). Red solid; yield: $85 \%$; ${ }^{1} \mathrm{H}$ NMR (400 MHz, DMSO- $\left.d_{6}, \mathrm{ppm}\right): \delta=8.30\left(\mathrm{~d},{ }^{3} J=\right.$ $15.7 \mathrm{~Hz}, 1 \mathrm{H}), 7.90$ (d, $\left.{ }^{3} J=15.7 \mathrm{~Hz}, 1 \mathrm{H}\right), 7.80$ (d, $\left.{ }^{3} J=8.8 \mathrm{~Hz}, 2 \mathrm{H}\right)$, $7.16\left(\mathrm{~d},{ }^{3} J=15.7 \mathrm{~Hz}, 1 \mathrm{H}\right), 7.06\left(\mathrm{~d},{ }^{3} J=8.8 \mathrm{~Hz}, 2 \mathrm{H}\right), 6.99\left(\mathrm{~d},{ }^{3} J=15.8\right.$ Hz, 1H), 6.47 (s, 2H), 6.35 (s, 1H), 3.95 (s, 6H), 3.90 (s, 3H), 3.84 (s, 3H); satisfactory ${ }^{13} \mathrm{C}$ NMR spectra could not be obtained; ${ }^{19} \mathrm{~F}$ NMR (235 MHz, $\left.\mathrm{CDCl}_{3}\right): \delta=-141.59\left({ }^{10} \mathrm{~B}-\mathrm{F}, 0.2\right),-141.65 \mathrm{ppm}$ $\left({ }^{11} \mathrm{~B}-\mathrm{F}, 0.8\right)$. HRMS $\left(\mathrm{ESI}^{+}\right)[\mathrm{M}+\mathrm{Na}]^{+}$calcd for $\mathrm{C}_{23} \mathrm{H}_{23} \mathrm{O}_{6} \mathrm{BF}_{2} \mathrm{Na}^{+} m / z=$ 467.1452, found $m / z=467.1453$.

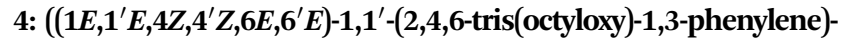
bis(5-(difluoroboryloxy)-7-(4-methoxyphenyl)hepta-1,4,6-trien-3one)). Red solid; yield: 97\%; ${ }^{1} \mathrm{H}$ NMR (400 MHz, DMSO, ppm): $\delta=8.25\left(\mathrm{~d},{ }^{3} J=16 \mathrm{~Hz}, 2 \mathrm{H}\right), 7.97\left(\mathrm{~d},{ }^{3} J=15.5 \mathrm{~Hz}, 2 \mathrm{H}\right), 7.55$ (d, $\left.{ }^{3} J=8.5 \mathrm{~Hz}, 4 \mathrm{H}\right), 7.14\left(\mathrm{~d},{ }^{3} J=16 \mathrm{~Hz}, 2 \mathrm{H}\right), 6.93\left(\mathrm{~d},{ }^{3} J=8.5 \mathrm{~Hz}\right.$, $4 \mathrm{H}), 6.54\left(\mathrm{~d},{ }^{3} J=15.5 \mathrm{~Hz}, 2 \mathrm{H}\right), 6.26(\mathrm{~s}, 1 \mathrm{H}), 5.56(\mathrm{~s}, 1 \mathrm{H}), 4.14$ $\left(\mathrm{t},{ }^{3} J=6.5 \mathrm{~Hz}, 4 \mathrm{H}\right), 3.85(\mathrm{~s}, 6 \mathrm{H}), 3.80\left(\mathrm{t},{ }^{3} J=6.5 \mathrm{~Hz}, 2 \mathrm{H}\right), 1.92$ $(\mathrm{m}, 6 \mathrm{H}), 1.32(\mathrm{~m}, 30 \mathrm{H}), 0.90 \mathrm{ppm}(\mathrm{m}, 9 \mathrm{H})$; satisfactory ${ }^{13} \mathrm{C} \mathrm{NMR}$ spectra could not be obtained; ${ }^{19} \mathrm{~F}$ NMR (235 MHz, DMSO): $\delta=-140.91\left({ }^{10} \mathrm{~B}-\mathrm{F}, 0.2\right),-140.97 \mathrm{ppm}\left({ }^{11} \mathrm{~B}-\mathrm{F}, 0.8\right)$. HRMS $\left(\mathrm{ESI}^{+}\right)$ $[\mathrm{M}+2 \mathrm{Na}]^{2+}$ calcd for $\mathrm{C}_{58} \mathrm{H}_{76} \mathrm{O}_{9} \mathrm{~B}_{2} \mathrm{~F}_{4} \mathrm{Na}_{2}{ }^{2+} \mathrm{m} / z=530.2707$, found $m / z=530.2705$.

\section{Acknowledgements}

The authors want to thank Dr Wladimir Marine for his help in setting up the two-photon excitation set-up.

\section{References}

1 Z. Guo, S. Park, J. Yoon and I. Shin, Chem. Soc. Rev., 2014, 43, 16-29.

2 A. B. Ormond and H. S. Freeman, Materials, 2013, 6, 817-840.

3 S. S. Kelkar and T. M. Reineke, Bioconjugate Chem., 2011, 22, 1879-1903.

4 P.-A. Bouit, G. Wetzel, G. R. Berginc, B. Loiseaux, L. C. Toupet, P. Feneyrou, Y. Bretonnière, K. Kamada, O. Maury and C. Andraud, Chem. Mater., 2007, 19, 5325-5335.

5 M. Liang and J. Chen, Chem. Soc. Rev., 2013, 42, 3453-3488. 6 A. Zitzler-Kunkel, M. R. Lenze, N. M. Kronenberg, A.-M. Krause, M. Stolte, K. Meerholz and F. Würthner, Chem. Mater., 2014, 26, 4856-4866.

7 A. Mishra and P. Bäuerle, Angew. Chem., Int. Ed., 2012, 51, 2020-2067.

8 A. Loudet and K. Burgess, Chem. Rev., 2007, 107, 4891-4932.

9 G. Ulrich, R. Ziessel and A. Harriman, Angew. Chem., Int. Ed., 2008, 47, 1184-1201.

10 R. Ziessel, G. Ulrich and A. Harriman, New J. Chem., 2007, 31, 496-501.

11 N. Boens, V. Leen and W. Dehaen, Chem. Soc. Rev., 2012, 41, 1130-1172.

12 A. D'Aléo and F. Fages, Disp. Imaging, 2014, 2, 149-174.

13 E. Cogné-Laage, J.-F. Allemand, O. Ruel, J.-B. Baudin, V. Croquette, M. Blanchard-Desce and L. Jullien, Chem. Eur. J., 2004, 10, 1445-1455.

14 A. D'Aleo, A. Felouat, V. Heresanu, A. Ranguis, D. Chaudanson, A. Karapetyan, M. Giorgi and F. Fages, J. Mater. Chem. C, 2014, 2, 5208-5215. 
15 N. D. Nguyen, G. Zhang, J. Lu, A. E. Sherman and C. L. Fraser, J. Mater. Chem., 2011, 21, 8409-8415.

16 G. Zhang, J. P. Singer, S. E. Kooi, R. E. Evans, E. L. Thomas and C. L. Fraser, J. Mater. Chem., 2011, 21, 8295-8299.

17 A. D’Aléo, D. Gachet, V. Heresanu, M. Giorgi and F. Fages, Chem. - Eur. J., 2012, 18, 12764-12772.

18 A. D’Aléo, V. Heresanu, M. Giorgi, B. Le Guennic, D. Jacquemin and F. Fages, J. Phys. Chem. C, 2014, 118, 11906-11918.

19 G. Bai, C. Yu, C. Cheng, E. Hao, Y. Wei, X. Mu and L. Jiao, Org. Biomol. Chem., 2014, 12, 1618-1626.

20 X. Cheng, D. Li, Z. Zhang, H. Zhang and Y. Wang, Org. Lett., 2014, 16, 880-883.

21 J. Hu, Z. He, Z. Wang, X. Li, J. You and G. Gao, Tetrahedron Lett., 2013, 54, 4167-4170.

22 C. Ran, X. Xu, S. B. Raymond, B. J. Ferrara, K. Neal, B. J. Bacskai, Z. Medarova and A. Moore, J. Am. Chem. Soc., 2009, 131, 15257-15261.

23 X. Zhang, Y. Tian, Z. Li, X. Tian, H. Sun, H. Liu, A. Moore and C. Ran, J. Am. Chem. Soc., 2013, 135, 16397-16409.

24 A. Pfister, G. Zhang, J. Zareno, A. F. Horwitz and C. L. Fraser, ACS Nano, 2008, 2, 1252-1258.

25 S. Chambon, A. D'Aléo, C. Baffert, G. Wantz and F. Fages, Chem. Commun., 2013, 49, 3555-3557.

26 A. M. Sarker, E. E. Gürel, M. Zheng, P. M. Lahti and F. E. Karasz, Macromolecules, 2001, 34, 5897-5901.

27 A. Felouat, A. D'Aléo and F. Fages, J. Org. Chem., 2013, 78, 4446-4455.

28 G. Mann, L. Beyer and A. Arrieta, Z. Chem., 1987, 27, 172-173.
29 Z. R. Grabowski, K. Rotkiewicz and W. Rettig, Chem. Rev., 2003, 103, 3899-4031.

30 C. Xu and W. W. Webb, J. Opt. Soc. Am. B, 1996, 13, 481-491.

31 J. A. Tiburcio-Moreno, J. J. Alvarado-Gil, C. Diaz, L. Echevarria and F. E. Hernández, Chem. Phys. Lett., 2013, 583, 160-164.

32 H. Hu, O. V. Przhonska, F. Terenziani, A. Painelli, D. Fishman, T. R. Ensley, M. Reichert, S. Webster, J. L. Bricks, A. D. Kachkovski, D. J. Hagan and E. W. Van Stryland, Phys. Chem. Chem. Phys., 2013, 15, 7666-7678.

33 W. M. McClain, Acc. Chem. Res., 1974, 7, 129-135.

34 F. Terenziani, A. Painelli, C. Katan, M. Charlot and M. Blanchard-Desce, J. Am. Chem. Soc., 2006, 128, 15742-15755.

35 Q. Bellier, N. S. Makarov, P.-A. Bouit, S. Rigaut, K. Kamada, P. Feneyrou, G. Berginc, O. Maury, J. W. Perry and C. Andraud, Phys. Chem. Chem. Phys., 2012, 14, 15299-15307.

36 H. Kawai, H. S. Nalwa, H. Oikawa, S. Okada, H. Matsuda, N. Minami, A. Kakuda, K. Ono, A. Mukoh and H. Nakanishi, Jpn. J. Appl. Phys., 1992, 31, L1132-L1134.

37 C. A. Parker, Photoluminescence of Solutions, Elsevier Publishing, Amsterdam, 1969.

38 J. R. Lakowicz, Principles of Fluorescence Spectroscopy, Kluwer, NewYork (NY), 2006.

39 N. G. Connelly and W. E. Geiger, Chem. Rev., 1996, 96, 877-910. 40 Y. Zuo, J. Huang, B. Zhou, S. Wang, W. Shao, C. Zhu, L. Lin, G. Wen, H. Wang, J. Du and X. Bu, Eur. J. Med. Chem., 2012, 55, 346-357.

41 S. B. Bharate, R. Mudududdla, R. Sharma and R. A. Vishwakarma, Tetrahedron Lett., 2013, 54, 2913-2915. 